\title{
Fiberoptic laryngoscopy-- experience in a private hospital
}

\author{
KMM Murshed ${ }^{1}$, MHAR Talukder ${ }^{2}, \mathrm{H} \mathrm{Rahman}^{3}$, AKM S Uddin ${ }^{4}$
}

\begin{abstract}
Background: Laryngoscopy is a medical procedure used to obtain a view from nose to voice box (larynx). A thin, lighted tube is usedto view the anatomical detailof the nose, nasopharynx, pharynx andvoice box including motion of the vocal cords in fibreoptic laryngoscopy. Biopsy can also be taken from the suspected lesions. The procedure is usually performed as an OPD procedure under local anesthesia. Methodology: This retrospective, cross sectional observational studywas conducted from June 2007 to October 2015 in a private hospital. Results: 12265 patients were examined and 625 patientsunderwent biopsy during the procedure. Among them male was $55.39 \%$ and female was $44.61 \%$. Findings were revealed normal in $69.80 \%$,benign looking lesionsin $11.61 \%$, suspected growth in $16.87 \%$ of the cases. $54.24 \%$ were histologically positive for malignancy. Conclusion: Fiberopticlaryngoscopyis a very effective in-office or outdoor procedure for examination of the nose, nasopharynx, pharynx and larynxand also for taking biopsy from the suspected lesions under local anesthesia. [J Shaheed Suhrawardy Med Coll 2015;5(2): 59-62]
\end{abstract}

Keywords: Fiberopticlaryngoscopy, larynx, biopsy.

Received: August 2012; Revised: October 2013; Accepted: November 2013

\section{Introduction}

Laryngoscopyis a visual examination of the nose, nasopharynx, pharynx and voice box (larynx) containing the vocal cords ${ }^{1}$. The three kinds of laryngoscopy are: indirect laryngoscopy, fiber-optic (flexible) laryngoscopy and direct (rigid) laryngoscopy ${ }^{2}$.

The indirect procedure can be performed in a doctor's office using a small hand mirror or a head light to examine the larynx and vocal cords. A rigid viewing tube may be passed through the mouth for a more thorough inspection, a procedure called rigid laryngoscopy ${ }^{3}$, which is more often used as part of a surgical procedure in evaluating kids with stridor (a noisy, harsh breathing), removing foreign objects from throat and lower airway ${ }^{4}$, collecting tissue samples (biopsies) and laser treatmentsunder general anesthesia.
In flexible laryngoscopy, a thin, flexible optic tube (called a laryngoscope) is passed through the nose and guided to the larynx. Fiberopticlaryngoscopy (FOL) permits a physician to directly inspect the anatomical detail and function of the nose, nasopharynx, pharynx and voice box (larynx) under local anaesthesia. FOL has been used to guide various in-office procedures for the last 3 decades ${ }^{7}$. Since first described in the early 1970s 7 , it is an effective procedure for discovering the causes of voice and breathing problems, throat or ear pain, difficulty in swallowing, narrowing of the throat (strictures or stenosis), airway blockages ${ }^{3}$ and taking laryngeal biopsy ${ }^{5,6}$. FOL is ain-office procedure can effectively be used for taking biopsy $^{7}$ and for removing foreign body from hypopharynx and larynx.

1. Dr. K M Mamun Murshed, Assistant professor of ENT cum Assistant Director, ShSMCH

2. Dr. Md. HarunAr Rashid Talukder, Jr. Consultant, ENT Dept, NIO, Dhaka.

3. Dr. HabiburRahman, Lecturer, Anatomy, ShSMC

4. Dr. A K M ShaifUddin, Jr. consultant, ENT Dept, ShSMCH

\section{Correspondence}

Dr. K M Mamun Murshed, Assistant professor of ENT cum Assistant Director, ShSMCH, Dhaka. Email- murshedmamun@yahoo.com.Ph: +8801777380677 . 
Photograph 1 \& 2 : Huge abdominal lump
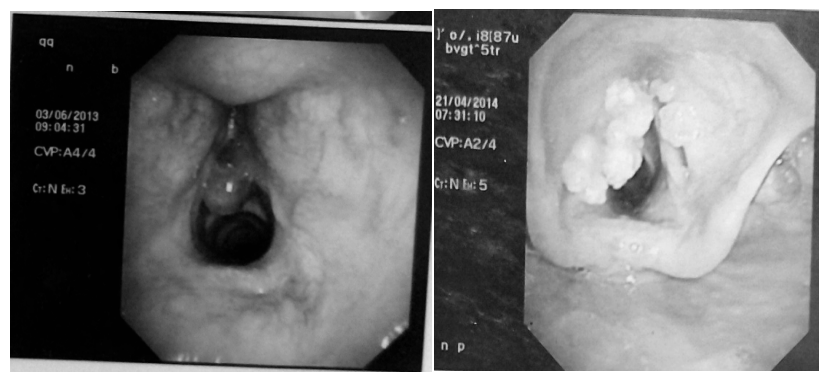

Fig- Vocal cord polyp

Fig - Vocal cord growth

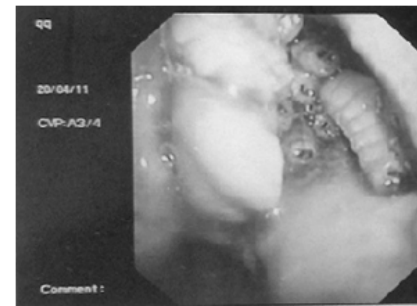

Fig- Maggots in nasopharynx

\section{Methodology}

This is a retrospective, cross sectional observational study conducted on the basis of FOL examination (using Olympus CV-150) and biopsy, as aOPD procedure inLabaid Specialized hospital, Dhanmondi, Dhaka from July 2007 to October 2015. Here, 12265 patients were examined in this period. Each patient was counseledabout the procedure and verbal consent was taken for biopsy if needed. The procedure was done under 10\% Lidocain spray. Biopsy was taken from 625 patients with suspected growth during the procedure. All the findings were properly written in prescribed data collection sheet and biopsy specimen were properly preserved in preservative material and was sent for histopathological examinations. Collected data were analyzed.

\section{Results}

A total number of 12265 patients underwent FOL. The age range was from 4 to 83 years. Majority of the patients were between the 16 to 65 years age groups with highest number in 26-35 year age group. Male (55.39\%)outnumbered female $(44.61 \%)$. Smoking and or betel nut chewing were the predominant personal habits of the patients examined. Foreign body sensation, feeling something in the throat and pain were the main complaints of the patients. Voice abusers or chemical and garments workers were main sufferers $(40.48 \%)$ of laryngeal problems. FOL revealed suspected growth in $16.87 \%$ and benign looking lesions like vocal cord polyp, noduleor Reinke's edema or others in $11.61 \%$ of the cases. In $69.80 \%$ of the patients,FOL revealed no abnormalities. A number of 348 diagnosed post treated cancer patients underwent follow up FOL and revealed recurrent growth in $143(41.09 \%)$ cases.Biopsy was taken from suspected growth in 625 patients during the procedure. Among them,54.24\% were histologically positive for malignancy.
Table IAge distribution of the patients (n- 12265)

\begin{tabular}{|c|c|c|c|c|c|c|c|c|c|}
\hline Year & $>5 \mathrm{yr}$ & $5-15 y r$ & $16-25 \mathrm{yr}$ & 26-35yr & $36-45 y r$ & $46-55 \mathrm{yr}$ & $56-65 \mathrm{yr}$ & $66-75 \mathrm{yr}$ & $\overline{76 y r s+}$ \\
\hline 2007 & - & 10 & 169 & 174 & 202 & 195 & 446 & 20 & 27 \\
\hline 2008 & 2 & 35 & 272 & 235 & 235 & 191 & 157 & 38 & 61 \\
\hline 2009 & - & 53 & 280 & 378 & 311 & 325 & 295 & 52 & 40 \\
\hline 2010 & 10 & 55 & 311 & 353 & 420 & 388 & 371 & 78 & 63 \\
\hline 2011 & 2 & 26 & 234 & 385 & 365 & 275 & 252 & 71 & 27 \\
\hline 2012 & 3 & 29 & 284 & 301 & 278 & 243 & 190 & 52 & 42 \\
\hline 2013 & 1 & 27 & 221 & 252 & 226 & 259 & 123 & 32 & 35 \\
\hline 2014 & 6 & 32 & 171 & 255 & 249 & 248 & 173 & 49 & 23 \\
\hline 2015 & 5 & 25 & 147 & 208 & 210 & 165 & 77 & 35 & 16 \\
\hline \multirow[t]{2}{*}{ Total } & 29 & 292 & 2089 & 2541 & 2496 & 2289 & 2084 & 427 & 334 \\
\hline & $(0.23 \%)$ & $(2.38 \%)$ & $(17.03 \%)$ & $(20.71 \%)$ & $(20.35 \%)$ & $(18.66 \%)$ & $(16.99 \%)$ & $(3.48 \%)$ & $(2.72 \%)$ \\
\hline
\end{tabular}

TableII. Sexdistribution of the patients (n- 12265)

\begin{tabular}{l|c|c|c}
\hline Year & Number of & \multicolumn{2}{|c}{ Sex } \\
\cline { 3 - 4 } & patients & Male & Female \\
\hline 2007 & 898 & 576 & 322 \\
2008 & 1307 & 697 & 610 \\
2009 & 1769 & 878 & 891 \\
2010 & 2095 & 1183 & 912 \\
2011 & 1524 & 813 & 711 \\
2012 & 1437 & 938 & 499 \\
2013 & 1141 & 668 & 474 \\
2014 & 1206 & 629 & 577 \\
2015 & 888 & 412 & 476 \\
\hline Total & $\mathbf{1 2 2 6 5}$ & $\mathbf{6 7 9 4}(55.39 \%)$ & $\mathbf{5 4 7 1}(44.61 \%)$ \\
\hline
\end{tabular}

Table III Personal habits of the patients (n-12265)

\begin{tabular}{l|c|c|c|c|c}
\hline \multirow{2}{*}{ Year } & \multicolumn{5}{|c}{ Sex } \\
\cline { 2 - 6 } & Smoking & Betel nut & Alcohol & Oth./Comb. & None \\
\hline 2007 & 167 & 245 & 19 & 270 & 197 \\
2008 & 236 & 218 & 21 & 306 & 526 \\
2009 & 295 & 268 & 26 & 223 & 957 \\
2010 & 321 & 343 & 21 & 256 & 1154 \\
2011 & 327 & 294 & 33 & 255 & 615 \\
2012 & 258 & 271 & 25 & 265 & 618 \\
2013 & 191 & 98 & 31 & 165 & 656 \\
2014 & 174 & 128 & 17 & 159 & 728 \\
2015 & 103 & 199 & 11 & 210 & 365 \\
\hline Total & $\mathbf{2 0 7 2 ( 1 6 . 8 9 \% )}$ & $\mathbf{2 0 6 4 ( 1 6 . 8 2 \% )}$ & $\mathbf{2 0 4 ( 1 . 6 6 \% )}$ & $\mathbf{2 1 0 9 ( 1 7 . 1 9 \% )}$ & $\mathbf{5 8 1 6 ( 4 7 . 4 1 \% )}$ \\
\hline
\end{tabular}


Table III Personal habits of the patients (n-12265)

\begin{tabular}{c|c|c|c|c|c|c}
\hline Year & \multicolumn{3}{|c|}{ Male (n- 6794) } & \multicolumn{3}{c}{ Female (n- 5471) } \\
\cline { 2 - 7 } & $\begin{array}{c}\text { Office } \\
\text { workers }\end{array}$ & $\begin{array}{c}\text { Voice abusers, } \\
\text { chemical/ } \\
\text { garments } \\
\text { workers }\end{array}$ & $\begin{array}{c}\text { Business/ } \\
\text { others }\end{array}$ & $\begin{array}{c}\text { Office } \\
\text { workers }\end{array}$ & $\begin{array}{c}\text { Voice abusers, } \\
\text { chemical } \\
\text { garments } \\
\text { workers }\end{array}$ & $\begin{array}{c}\text { Business/ } \\
\text { others }\end{array}$ \\
\hline 2007 & 145 & 211 & 221 & 78 & 194 & 50 \\
2008 & 121 & 298 & 278 & 134 & 292 & 184 \\
2009 & 279 & 311 & 288 & 169 & 479 & 243 \\
2010 & 364 & 408 & 411 & 198 & 431 & 283 \\
2011 & 267 & 296 & 250 & 116 & 310 & 285 \\
2012 & 267 & 313 & 358 & 176 & 216 & 107 \\
2013 & 135 & 287 & 246 & 117 & 221 & 135 \\
2014 & 176 & 243 & 210 & 141 & 242 & 194 \\
2015 & 88 & 125 & 199 & 172 & 190 & 114 \\
\hline Total & $\mathbf{1 8 4 2}$ & $\mathbf{2 4 9 1}$ & $\mathbf{2 4 6 1}$ & $\mathbf{1 3 0 1}$ & $\mathbf{2 4 7 5}$ & $\mathbf{1 6 9 5}$ \\
\hline
\end{tabular}

TableII. Sexdistribution of the patients (n- 12265)

\begin{tabular}{l|c}
\hline Complaints & No of patients \\
\hline Change of voice & 9784 \\
Feeling something in the throat & 10877 \\
Pain in the throat & 11324 \\
Difficulty in swallowing & 4612 \\
Neck swelling & 1387 \\
Globus/ Foreign body sensation in throat & 9134 \\
Respiratory difficulty & 1321 \\
H/O Foreign body ingestion & 32 \\
H/O Previous carcinoma larynx/hypopharynx & 348 \\
Nasal bleeding & 145 \\
Nasal obstruction & 1892 \\
Others & 987 \\
\hline
\end{tabular}

N.B- Most of the patients came with multiple complaints

Table VI AFOL Findings (n- 12265)

\begin{tabular}{l|c|c|c|c|c}
\hline \multirow{2}{*}{ Year } & \multicolumn{5}{|c}{ Findings } \\
\cline { 2 - 6 } & Normal & $\begin{array}{c}\text { Vocal cord } \\
\text { polyp }\end{array}$ & $\begin{array}{c}\text { Vocal cord } \\
\text { nodule }\end{array}$ & $\begin{array}{c}\text { Reinke's Edema/ } \\
\text { Vallecular cyst/others }\end{array}$ & $\begin{array}{c}\text { Phonatory } \\
\text { gap }\end{array}$ \\
\hline 2007 & 499 & $\mathbf{6 0}$ & 72 & $\mathbf{1 1}$ & 46 \\
2008 & 897 & $\mathbf{3 1}$ & 21 & $\mathbf{1 7}$ & 54 \\
2009 & 1132 & $\mathbf{5 3}$ & 46 & $\mathbf{2 1}$ & 29 \\
2010 & 1498 & $\mathbf{5 5}$ & 91 & $\mathbf{1 9}$ & 34 \\
2011 & 1179 & $\mathbf{5 4}$ & 50 & $\mathbf{1 4}$ & 48 \\
2012 & 1022 & $\mathbf{3 5}$ & 69 & $\mathbf{2 5}$ & 53 \\
2013 & 895 & $\mathbf{2 9}$ & 29 & $\mathbf{0 8}$ & 14 \\
2014 & 925 & $\mathbf{4 1}$ & 31 & $\mathbf{0 6}$ & 15 \\
2015 & 515 & $\mathbf{5 8}$ & 45 & $\mathbf{1 6}$ & 36 \\
\hline Total & $\mathbf{8 5 6 2 ( 6 9 . 8 0 \% )}$ & $\mathbf{4 1 6 ( 3 . 3 9 \% )}$ & $\mathbf{4 5 4 ( 3 . 7 0 \% )}$ & $\mathbf{1 3 7 ( 1 . 1 1 \% )}$ & $\mathbf{3 2 9 ( 2 . 6 8 \% )}$ \\
\hline
\end{tabular}

Table VI BFOL Findings (n-12265)

\begin{tabular}{|c|c|c|c|c|c|c|}
\hline \multirow[t]{3}{*}{ Year } & \multicolumn{6}{|c|}{ Findings } \\
\hline & \multirow{2}{*}{$\begin{array}{l}\text { Supra } \\
\text { glottic } \\
\text { growth }\end{array}$} & \multirow{2}{*}{$\begin{array}{l}\text { Glottic } \\
\text { growth }\end{array}$} & \multirow{2}{*}{\begin{tabular}{|c|} 
Pyriform \\
fossa growth
\end{tabular}} & \multirow{2}{*}{$\begin{array}{c}\text { Naso } \\
\text { pharyngeal } \\
\text { growth }\end{array}$} & \multicolumn{2}{|c|}{ Follow up FOL (n 348) } \\
\hline & & & & & $\begin{array}{c}\text { Recurrent } \\
\text { growth }\end{array}$ & $\begin{array}{c}\text { No growth } \\
\text { /edema }\end{array}$ \\
\hline 2007 & 84 & 18 & 56 & 05 & 12 & 16 \\
\hline 2008 & 95 & 37 & 73 & 11 & 04 & 10 \\
\hline 2009 & 129 & 76 & 113 & 19 & 21 & 32 \\
\hline 2010 & 99 & 48 & 108 & 12 & 19 & 29 \\
\hline 2011 & 37 & 12 & 35 & 14 & 11 & 21 \\
\hline 2012 & 42 & 11 & 49 & 07 & 15 & 19 \\
\hline 2013 & 46 & 19 & 44 & 05 & 08 & 13 \\
\hline 2014 & 39 & 17 & 46 & 14 & 13 & 37 \\
\hline 2015 & 75 & 11 & 58 & 03 & 14 & 28 \\
\hline Total & $646(\mathbf{5 . 2 6} \%)$ & $249(2.03 \%)$ & $582(4.74 \%)$ & $90(0.73 \%)$ & $143(41.09 \%)$ & $205(58.90 \%)$ \\
\hline
\end{tabular}

Table VI AFOL Findings (n- 12265)

\begin{tabular}{c|c|c|c|c|c}
\hline Year & \multirow{2}{*}{$\begin{array}{c}\text { Biopsy } \\
\text { taken }\end{array}$} & \multicolumn{4}{|c}{ Histopathology } \\
\cline { 3 - 6 } & & Benign & Malignant & TB & $\begin{array}{c}\text { Keratosis/squam } \\
\text { ous hyperplasia }\end{array}$ \\
\hline 2007 & $\mathbf{4 6}$ & 09 & 27 & 03 & 07 \\
2008 & 58 & 08 & 33 & 06 & 11 \\
2009 & 64 & 11 & 39 & - & 14 \\
2010 & 102 & 13 & 58 & 07 & 24 \\
2011 & 57 & 13 & 25 & - & 19 \\
2012 & 89 & 14 & 34 & 02 & 33 \\
2013 & 80 & 18 & 43 & - & 19 \\
2014 & 71 & 19 & 36 & 01 & 15 \\
2015 & 58 & 11 & 38 & 01 & 08 \\
\hline Total & $\mathbf{6 2 5}$ & $\mathbf{1 1 6 ( 1 8 . 5 6 \% )}$ & $\mathbf{3 3 9 ( 5 4 . 2 4 \% )}$ & $\mathbf{2 6 ( 4 . 1 6 \% )}$ & $\mathbf{1 5 0 ( 2 4 . 0 0 \% )}$ \\
\hline
\end{tabular}

\section{Discussion}

Since its introduction more than 150 years ago, laryngoscopy has undergone numerous changes in clinical application. Laryngoscopy was started as an indirect procedure with the manipulation of a laryngeal mirror performed on an awake patient and progressed to direct laryngoscopy,sometimes with an operating microscope under general anesthesia. Now-a-days office based procedure, flexible laryngoscopy is becoming popular. Throughout the globe otolaryngologists are using flexible fiberoptic laryngoscope for routine throat examination and performing biopsy from the suspected lesion, a simple and cost-effective procedure alternative to the traditional direct laryngoscopy in most of the cases, especially for patients who are not fit candidates for general anesthesia. In this country few government and some private set up are using FOL as a special procedure.

In this hospital FOL is used as routine in-office or OPD procedure.Patients from other hospitals or doctor'sconsultation center are also referred here. Most of the patients were 16-65years old with peak age incidence in 26-35 year group.The age distribution of the patients was consistent with similar studies7,8. Male $(55.39 \%)$ was more 
than that of female (44.61\%).Among them large number of patients $(69.80 \%)$ had normal findings. This huge number of normal findings may be due to the increased level of consciousness of both the patients and the referring physician about the benign and malignant pathology of the larynx and pharynx and increasing 'cancer fovea' among the common people.Endoscopically benign looking lesions were 1007 (8.21\%), phonatory gap 329 (2.68\%) and suspected malignant lesions 2019 (16.46\%). Biopsy was taken from 625 patients, among themmalignancy was foundin $54.24 \%$ and tuberculosis was revealed in $26(4.16 \%)$ of the biopsy specimen. This finding is nearly similar with a study8 done in Israel.Biopsy was taken in some of the suspected malignant cases as the patient or his attendant did not consented for taking biopsy. Follow up FOL of 348 post treated cancer patients revealed recurrent growth in 143 $(41.09 \%)$ patients and no growth or showed some degree of edema in $205(58.90 \%)$ patients.Recurrence of growth probably due aggressiveness of the disease or inadequate or treatment failure of the cancer.Smoking, betel nut chewing were the predominant habits of the study population which is similar to astudy8. It may be mentioned that these two personal habits are recognized as the etiological factors of neoplastic lesions in ENT and Head-Neck region especially in this subcontinent9. Voice abusers, chemical or garments workers were the main sufferers. Though the flexible laryngoscope is routinely introduced through nose, sometimes it showed difficultydue to gross septal deviation and some other nasal pathology. In those cases oral route was preferred. Occasionally minor bleeding was occurred during the procedure and managed conservatively. In a very few cases,taking biopsy were little difficult due to severe gag reflex, pain or non-cooperation of the patient and sometimes critical anatomical location of the growth.

\section{Conclusion}

Fiberoptic laryngoscopy is a very effective in-office or outdoor procedure for examination of nose, nasopharynx, pharynx and larynx andbiopsy specimen can also be obtained from the suspected lesion under local anesthesiaduring the procedure. Conventionally, biopsy is taken under general anaesthesia from the suspected lesions of the nasopharynx, larynx and hypopharynx which require hospital admission and stay in the hospital. So, if FOL is used judiciously not only for examination but also for obtaining biopsy, it would avoid unnecessary hospital admission and stay and would be cost effective as well in managing ENT and Head-Neck pathology. Moreover, FOL would be a beneficial procedureespecially for those who are not fit for general anesthesia. FOL is also suitable for follow up the post treated carcinoma patients.

\section{References}

1. Davidson TM, Bone RC, Nahum AM. Flexible fiberopticlaryngobronchoscopy.

Laryngoscope. 1974;84(11):1876-1882.

2. Zeitels SM, Franco RA Jr, Dailey SH, Burns JA, Hillman RE, Anderson RR. Office-based

treatment of glottal dysplasia and papillomatosis with the $585-\mathrm{nm}$ pulsed dye laser and local anesthesia. Ann OtolRhinolLaryngol.

2004;113(4):265- 276.

3. Zeitels SM, AkstLM, Bums JA, Hillman RE, Broadhurst MS, Anderson RR. Office-based 532-nm pulse KTP laser treatment of glottal papillomatosis and dysplasia. Ann OtolRhinolLaryngol. 2006;115(9):679-685.

4. Franco RA Jr. In-office laryngeal surgery with the $585-\mathrm{nm}$ pulsed dye laser. CurrOpin

Otolaryngol Head Neck Surg. 2007;15(6):387-393.

5. Omori K, Shinohara K, Tsuji T, Kojima H. Videoendoscopic laryngeal surgery. Ann Otol

rhinolLaryngol. 2000;109(2):149-155.

6. Woo P. Office-based laryngeal procedures. OtolaryngolClin North Am. 2006;39 (1):111-133.

7. Jacob T. C, Ahmad S, Dan M. F, Ziv Gil, Gilad H. Reliability of a Transnasal Flexible Fiberoptic In-Office Laryngeal Biopsy. JAMA Otolaryngol Head Neck Surg. 2013;139(4):341-345.

8. Cohen JT, Benyamini L. Transnasal Flexible Fiberoptic in-office Laryngeal Biopsies-Our Experience with 117 Patients with Suspicious Lesions. Rambam Maimonides Med J 2014;5(2):e0011.

9. Rao DN, Shroff PD, Chattopadhyay G, Dinshaw KA. Survival analysis of 5595 head and neck cancers- results of conventional treatment in a high-risk population. British Journal of Cancer. 1998; 77(9),1514-1518. 